\title{
AN EMPIRICAL STUDY ON GURU RAM RAI DURBAR: A LIVING HERITAGE
}

\author{
Ar. Ramanjyot Shrivastava \\ Professor \\ Himgiri Zee University, DDN
}

\author{
Prof.SYK Kulkarni \\ Professor(Retd) \\ IIT Roorkee
}

\begin{abstract}
Dr.Prabhjot Kaur
Director, IKGPTU, Mohali Campus-II
\end{abstract}

\begin{abstract}
Guru Ram Rai Durbar is one of the oldest built structures of Dehradun and a significant example of architectural amalgamation. The juxtaposition of architectural components of the various buildings present in Durbar precinct reveals a range of different architectural styles and impressions of art traditions prevailing at that time. The study helps in rediscovering the 'Guru Ram Rai Durbar', heritage lore of the city and identifies it as a Living Cultural Heritage site to be conserved for future. A comprehensive understanding of the Durbar through research and documentation leads to a sensitive conservation approach for Durbar.
\end{abstract}

Keywords- Living Cultural Heritage, Architectural amalgamation, arbesque, frescos, Garhwal School of Paintings, Documentation

\section{INTRODUCTION}

Dehradun, itself is comprised of two words-Dehra and Dun. Dehra is derived from 'Dera, which means a staying place meant for a temporary phase and Doon means a 'valley' (the lower plains in the foot hills of Himalayan mountain range). It was once a dense forest with dangerous wild life, in the period of Aurangzeb. Guru Ram Rai (the eldest son of $7^{\text {th }}$ Sikh guru Guru Har Rai ji), the Udaseen Guru was welcomed by emperor of Garhwal, Fateh Shah on orders of Aurangzeb and was allowed to come here to retire in the wilderness of the valley. The place where he pitched his Dera is now in the Khurbura locality of the town. He established Guru Ram Rai Durbar near Dhamawalan in Samvat 1733(1676 A.D.) and was completed by his fourth wife (Mata Punjab Kaur, in Samvat 1756(1699 A.D.). The Durbar Sahib is situated like a fort between walls and minarets. It is a unique example of Mughal-Sikh-Pahari Architectural-Cultural-Heritage.

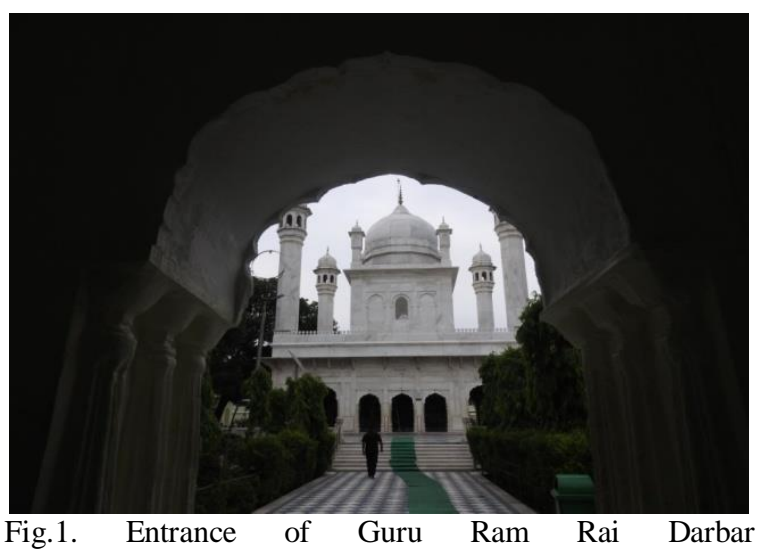

Source: Author

Important Dates Associated with the Evolution of Guru Ram Rai Durbar

- Guru Ram Rai came to Doon-1675 A.D.

- Durbar construction started under Aurangzeb in 1676 A.D.

- Guru Ram Rai died-1687 A.D.

- Durbar was completed by Mata Punjab Kaur1699 A.D.

- Mata Maluki Samadhi- 1724 A.D.

- Mata Lal Kaur Samadhi-1780 A.D.

- Mata Punjab Kaur Samadhi- 1811 A.D.

- Mata Raj Kaur Samadhi-1815 A.D.

- First Mahant on throne-1687 A.D.

- Embedding of marble initiated by Mahant Laxman Dass in -1896-2000

- Construction of new building completed in- 2011

- Repair, restoration, beautification by present Mahant Devendra Dass -Presently work in progress. 


\section{International Journal of Engineering Applied Sciences and Technology, 2019 \\ Vol. 4, Issue 8, ISSN No. 2455-2143, Pages 109-118 \\ Published Online December 2019 in IJEAST (http://www.ijeast.com)}

\section{Terms-}

1. Arabesque

A decorative form of Islamic Art, found on the ceiling of vestibules which echoes the forms of plants, flowers ,geometric shapes and animals especially birds.

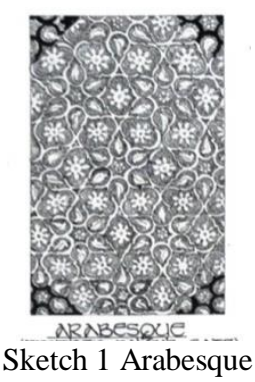

\section{Fresco-}

It is a technique of mural painting executed on freshly laid plaster. Word Fresco is derived from Italian adjective means fresh.

\section{Islamic Script -}

It is an art form, based on Arabic script.

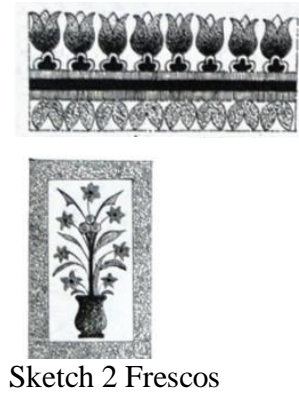

Sketch 2 Frescos

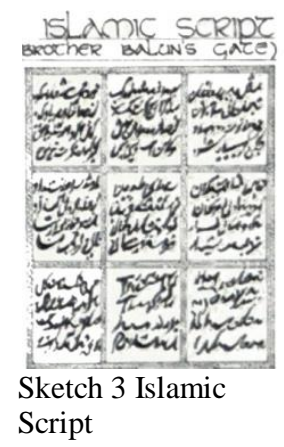

\section{A. Durbar and its Importance}

Gurudwara Ram Rai Durbar was established by Shri Guru Ram Rai. But Gurudwara converted to Shrine of Guru and his four wives, when English came to reign by defeating Nepal in 1816 . His followers have been known as Udasis or Ram Raiyyas, started their own traditions, separate from Sikhism and they follow the Sanatani way of life, worshipping the 'Mahants' who successively established Ram Rai's Gaddi after his death.

\section{B. Layout of Durbar}

Very similar to other mausoleums built by Mughals is the general layout of Guru Ram Rai mausoleum

and the adjoining garden. The design of Guru's Samadhi appears to have been inspired by Jahangir's Tomb at Shahdara Bagh, Lahore . Both the gardens, the one surrounding the monument and one adjoining, are strikingly Mughal in their Layout, representing the Charbagh or Four Gardens' concept (Been There Doon That.(2019). Whole complex is divided into three wings - Main Complex, Main Durbar wing and Mata's wing. Complex wing is entered by Elephant gate and consists of Museum, Office Building and Lungar Durbar Sahib. Main Durbar Wing has two entries-one from Complex wing through Darshini Dwar and second from Paltan Bazaar through Baluni Gate. Main Shrine of Guru and his four wives are well located in the whole complex. Mata's wing is a separate wing entered through Bhai Bheelon Gate where Mata Punjab Kaur's symbol of swing, Guru's cremation and Bathing area along with a step well are located.

\section{Jhanda Mela}

One of the famous fairs in North India, is the 'Jhanda Ka Mela' in Dehradun, an annual honored religious fair celebrated in February / March in the memory of Guru Ram Rai on his Birthday. Besides being the birthday of Guru Maharaj (Guru Ram Rai), it is also considered as the day of his arrival in Dehradun. In samvat 1733, on that day, the great occasion was celebrated in his honor and since then, the Jhanda is hoisted on every year to commemorate his sacred memory. Pilgrimages from Punjab, Haryana, Delhi, Uttar Pradesh and even from abroad arrive here few days prior to Jhanda hoisting. These crowds consist of men, women and children of all age groups and are called 'Sangat' (devotees, followers, admirers and saints).

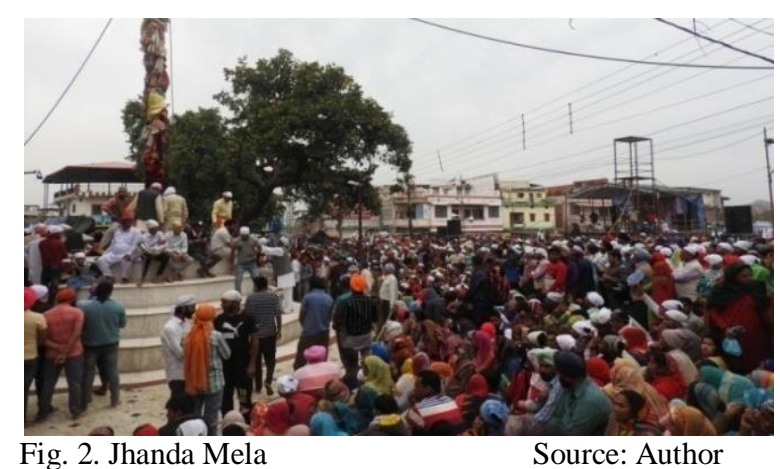

Fig. 2. Jhanda Mela 


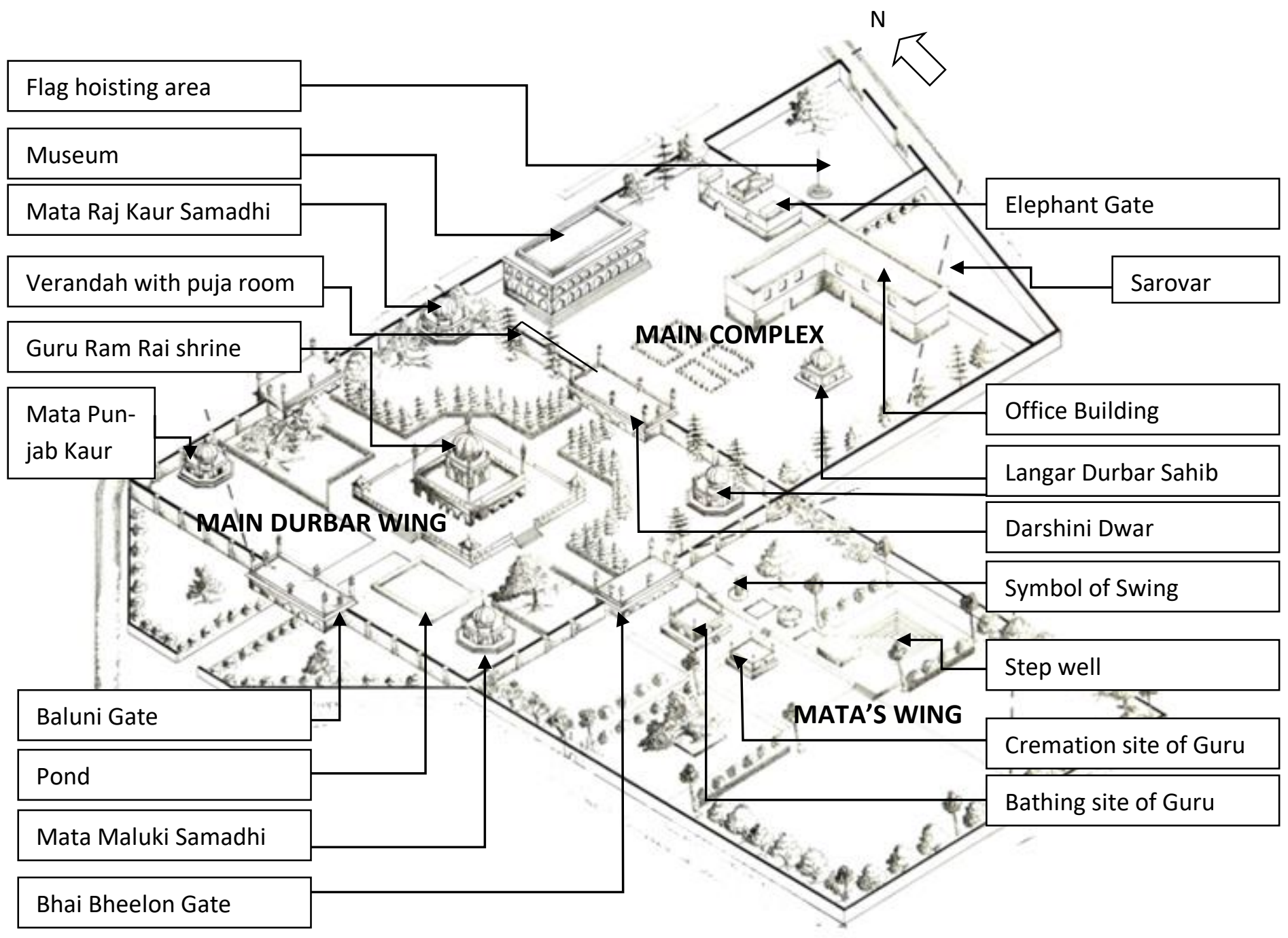

Sketch 4 Isometric view of Guru Ram Rai Darbar

\section{STUDY OF GURU RAM RAI DURBAR}

\section{MAIN COMPLEX}

Guru Ram Rai Durbar is one of the primordial buildings of Dehradun making deep instinct in terms of its being, religion, socio culture and architecture. Historic trademark has different influences for architecture in terms of invention of new techniques, historical facts and thus evolution of new architectural culture. The Durbar Sahib is situated in about one hundred bighas of land and enclosed within high walls. Durbar has many buildings which are living sculptures/ monuments as each and every measure and curve are handled with ingenuity. The huge sarovar in the front measuring 230x184 feet is as old as the Durbar. Lacs

\section{Source: Author} of Sangat take the holy dip during Mela in the sarovar.

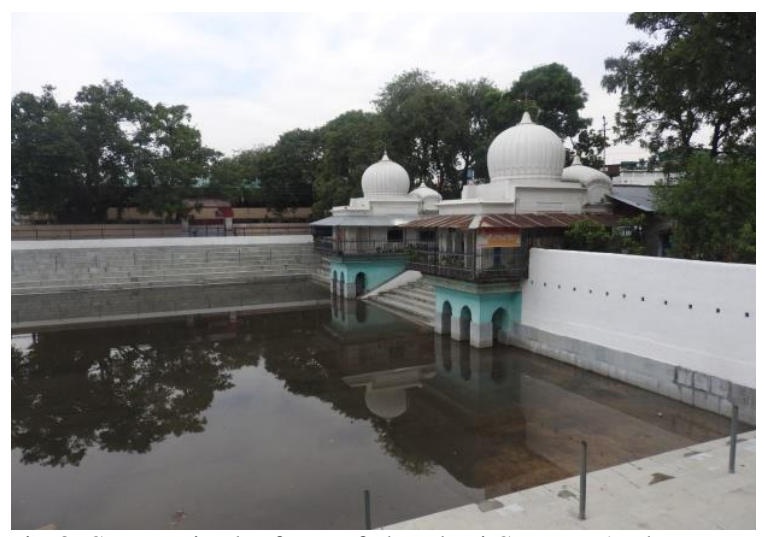

Fig.3. Sarovar in the front of Jhanda Ji Source: Author

\section{A. Elephant Gate}




\section{International Journal of Engineering Applied Sciences and Technology, 2019 \\ Vol. 4, Issue 8, ISSN No. 2455-2143, Pages 109-118 \\ Published Online December 2019 in IJEAST (http://www.ijeast.com)}

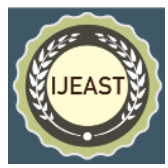

Entrance to the Durbar is through its Western Gate (Elephant Gate)*which is a specimen of Mughal and Rajasthani Style of Architecture. In its centre there is a place for the flag mast.

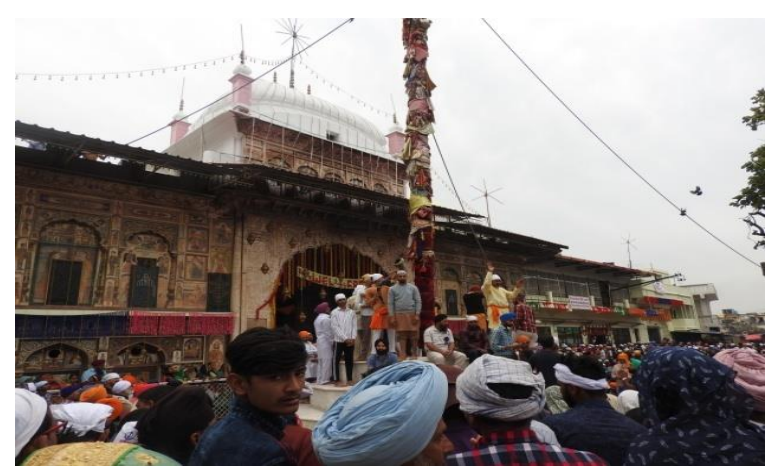

Fig.4. Elephant Gate on the West with place for flag mast in the centre Source: Author

Elephant gate is a splendid structure $6000 \mathrm{~mm}$ high and $3100 \mathrm{~mm}$ in width. Elephant gate were big enough for elephants to easily pass through.

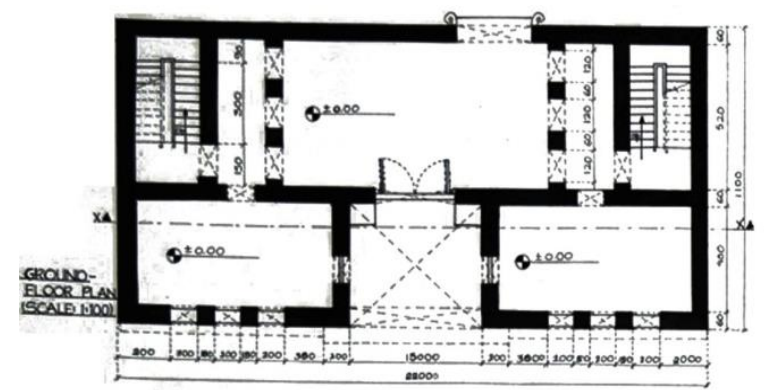

Sketch 5 Floor Plan of Elephant Gate Source: Author

The outer façade of elephant gate comprises of fusions and amalgamations of diverse architectural styles.

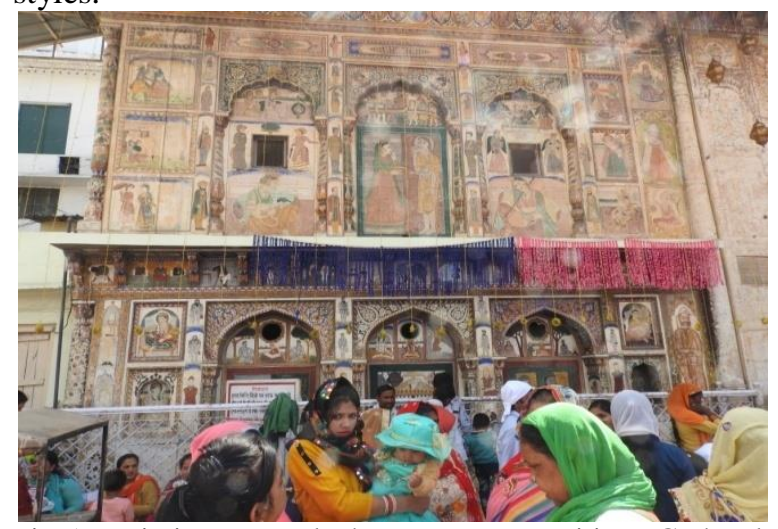

Fig.5. Paintings at Elephant gate portraiting Garhwal school of art Author
Walls and ceilings are profusely decorated with various paintings in bright natural colors depicting diverse mythological and historic events preserves the impressions of earlier art traditions. There are portraits of Gods, Goddesses, saints, sages and religious fables on the walls. There are pictures of flowers and leaves, animals and birds, trees, similar looking faces with pointed noses and big eyes on the arches which symbolizes the color scheme of Garhwal School of Painting

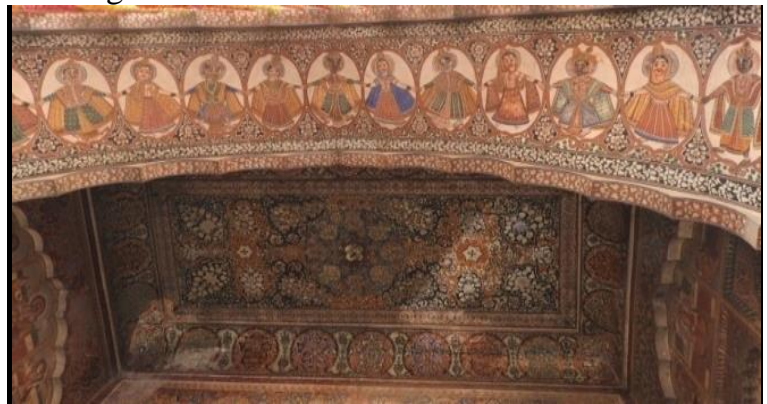

Fig.6. Ras lila and the painted ceiling at Durbar Gateway Source: Author

Garhwal School, is one of the lesser known schools of Pahari-Raput style of painting(Fig.7).It is a unique mix of Rajput-Pahari-Bashloi and Kangra schools. The distinctive features of the Garhwal School of Painting consist of extremely beautiful and near perfect women with high arched, thin and delicate looking eyebrows and a captivating nose with a defined nose bridge resting on a supple oval face. The build of the female would usually have a tiny waist emphasized by the greatly developed bosom.

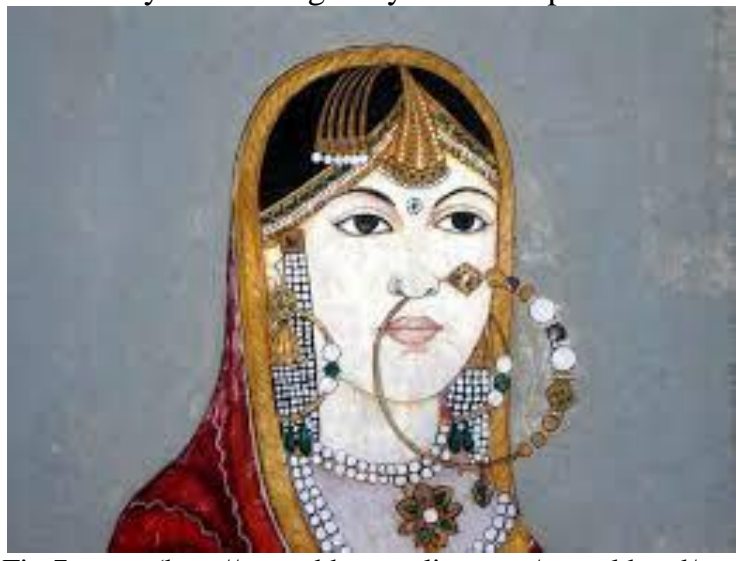

Fig.7. (http://www.bharatonline.com/uttarakhand/artscrafts/paintings.html)

Paintings are much more of an assemblage and depict Durbar as a true testimony in diversity. So are the colors and human forms. Diversity is mind boggling in such a way that you can see a lady in classical Mughal attire, wearing a large Garhwali nose ring and other ornaments.(Fig. 8). British ladies ready to 


\section{International Journal of Engineering Applied Sciences and Technology, 2019 \\ Vol. 4, Issue 8, ISSN No. 2455-2143, Pages 109-118 \\ Published Online December 2019 in IJEAST (http://www.ijeast.com)}

go for the horse races, rubbing shoulders with Naga Sadhus (Fig. 8 b.)
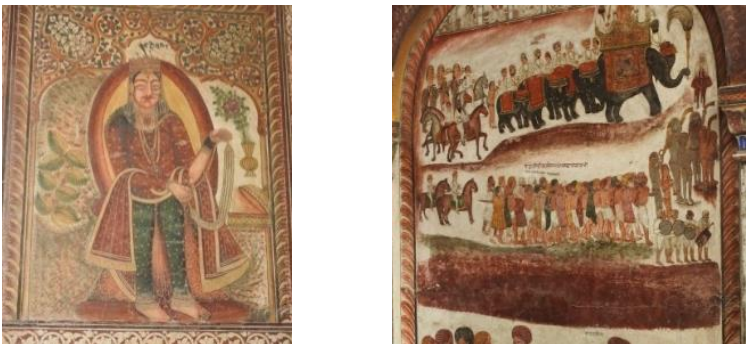

Fig 8(a) Lady in classical Mughal attire, wearing a large Garhwali nose ring and other ornaments.

Fig 8(b) British ladies ready to go for the horse races, rubbing shoulders with Naga Sadhus.

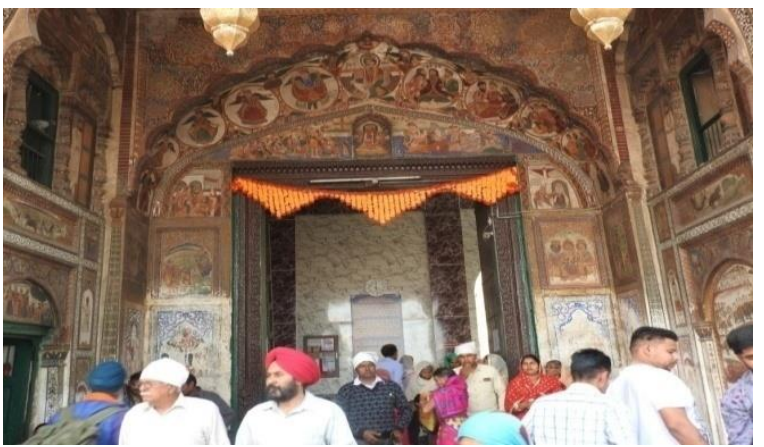

Fig.9. Entrance to Elephant gate Source: Author

On entering the main gate there is a large courtyard and to the left is a three storied building, which is used for office purpose. There is an open verandah in the right side of the courtyard and attached to it is a big hall named Museum with Guru Gaddi in it.

\section{B. Museum}

The portraits of all the Mahants are displayed on its walls. Religious meetings, discourses, festivals and functions are held. Museum is a two storied structure used as a sitting area by Shri Guru Ram Rai.

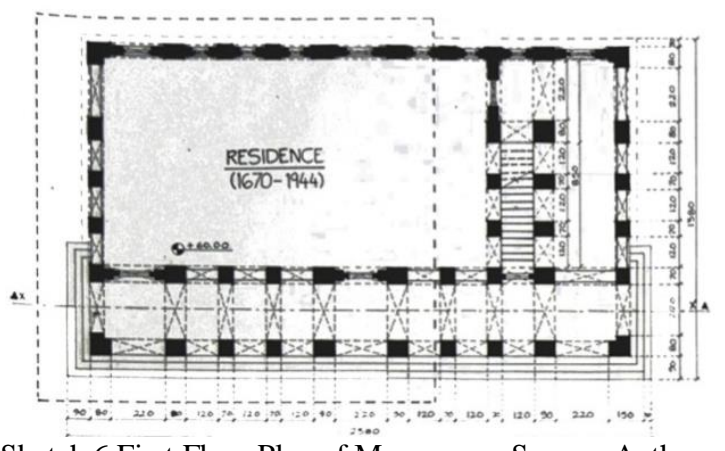

Sketch 6 First Floor Plan of Museum Source: Author

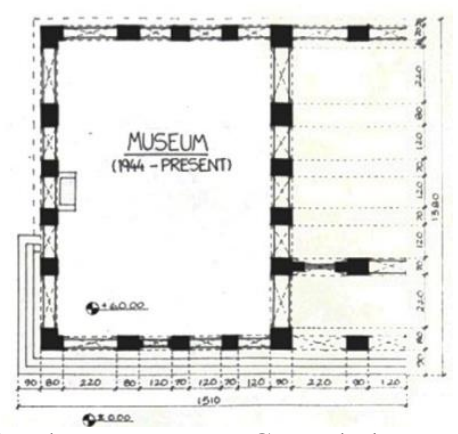

Sketch 7 Museum at Ground Floor

Floor comprises of an arcade restraining nine multi foil arches, influenced by Islamic Architecture.

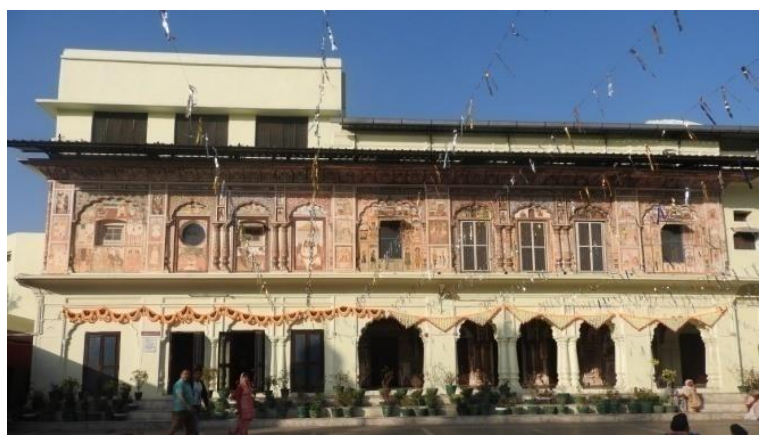

Fig.10. Museum with nine multifoil arches Source: Author

Inside the museum, ground floor exhibits paintings of all ten Mahants. On the façade frescos from tales of Hindu mythology and Sikh Guru sakhis are painted.
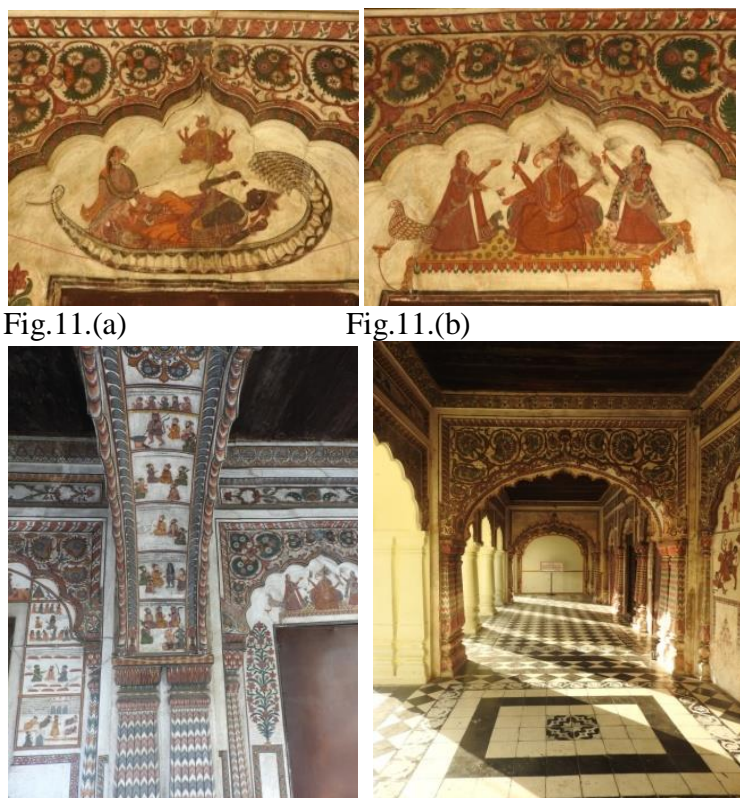

Fig.11.(b)

Fig.11.(c) Fig.11.(d)
Fig 11 (a),(b),(c),(d) Frescos from tales of Sikh Guru

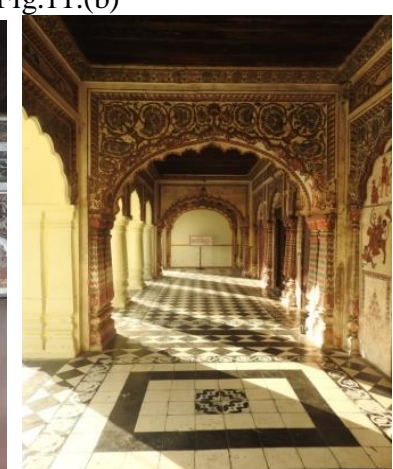

Sakhis and Hindu mythology 


\section{International Journal of Engineering Applied Sciences and Technology, 2019 \\ Vol. 4, Issue 8, ISSN No. 2455-2143, Pages 109-118 \\ Published Online December 2019 in IJEAST (http://www.ijeast.com)}

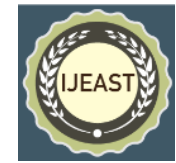

Source: Author

Towards the east, there is a long verandah with Puja Room, watchman's room, where devotees wait for the blessings of presentMahant ji. In the middle of the verandah and office building, there is a way to the Langar Sahib(community kitchen).

\section{Langar Durbar Sahib}

Langar Durbar Sahib at the back courtyard dwells as a place for food serving. It was earlier used by Matas as a worship place.

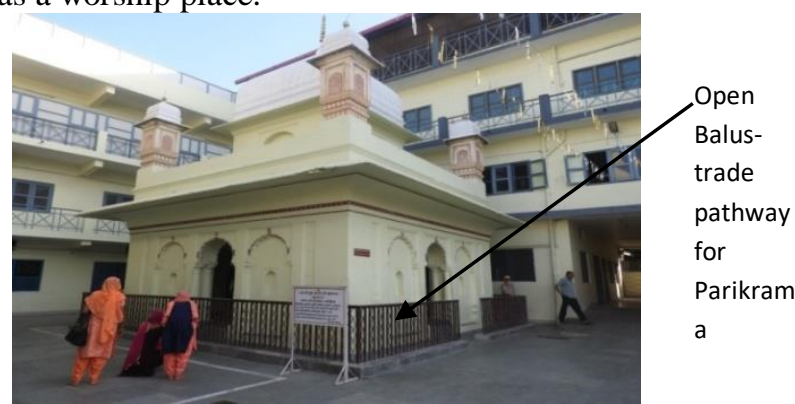

Fig.12. Langar Durbar Sahib Source: Author It rests on a square plan symmetrical about its entire axis.

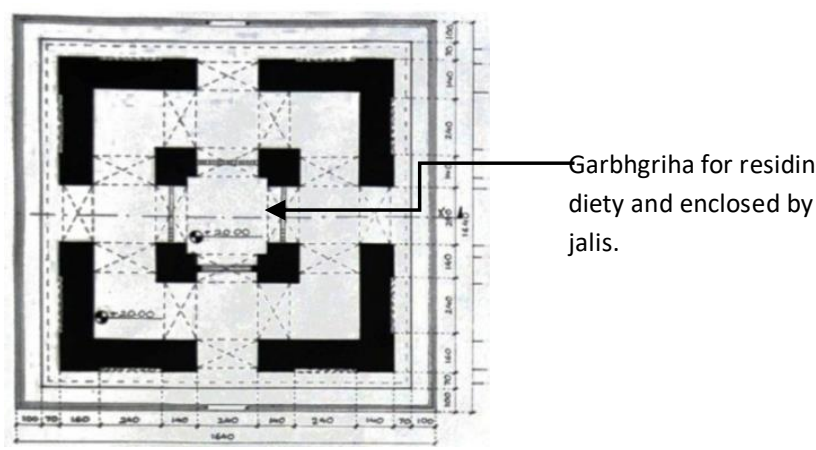

Sketch 8 Ground Floor Plan of Langar Darbar Sahib Source: Author

It comprises of outer balustrade pathway for parikrama and inside it located a square planned chamber enclosed by jali on three sides and a door on one which was earlier used as a garbhgriha for residing the Diety (Ganesha) as per Hindu Architecture.
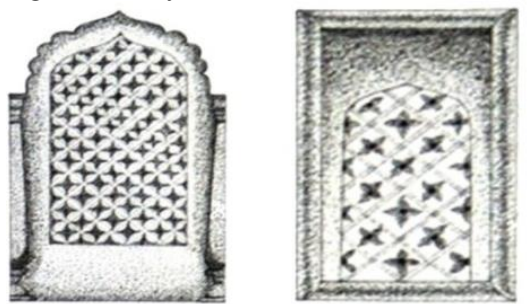

Sketch 9 Jalis enclosing Garbhgriha Source: Author

Towards the east, there is a passage that leads to the main building (Shrine) of the Durbar Sahib through Darshini Dwar/Gate.

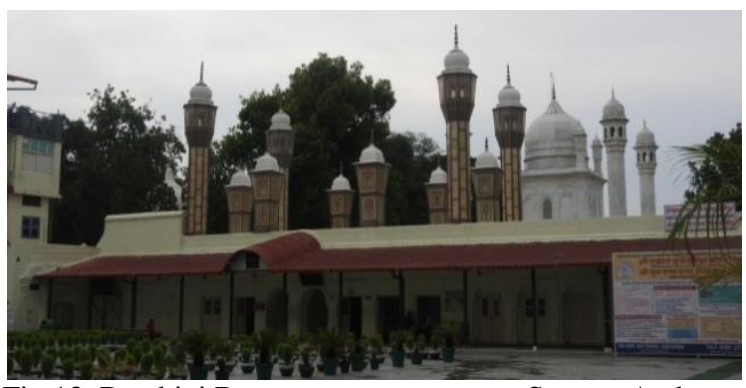

Fig.13. Darshini Dwar

Source: Author

\section{MAIN DURBAR WING}

\section{A. Darshini Dwar/Gate}

The main entrance of the Main Durbar wing is through an arcade consisting of seven multi foil arches in front, a characteristic of Mughal Architecture. On entering the first vestibule, there is a doorway and an arched opening on both sides which is the main gate to Durbar called Darshini Gate.

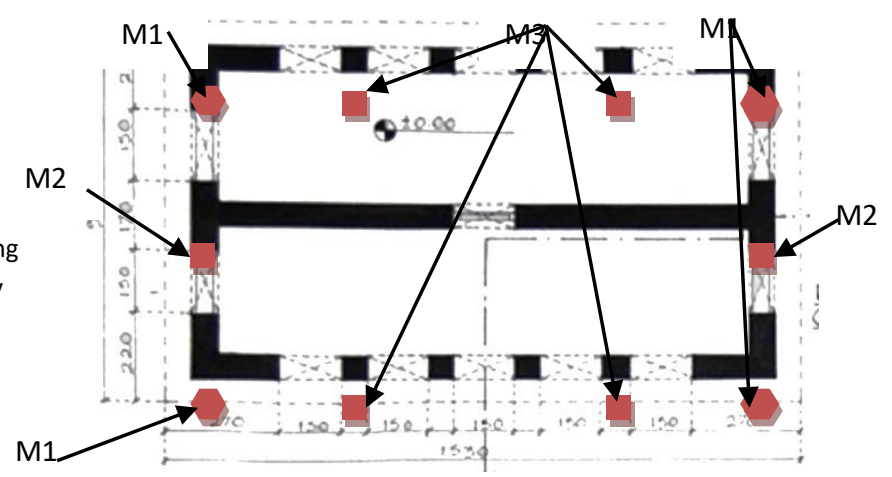

Sketch 10 Floor Plan of Darshini Dwar

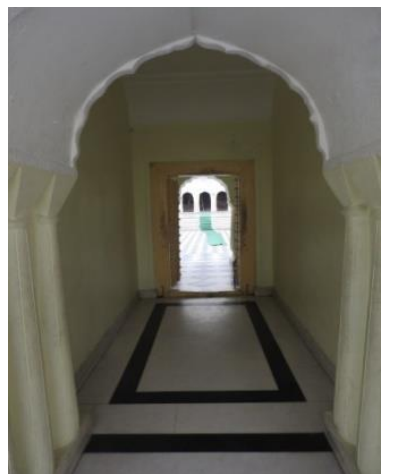

Fig.14(a). Main Gate to Durbar Source: Author

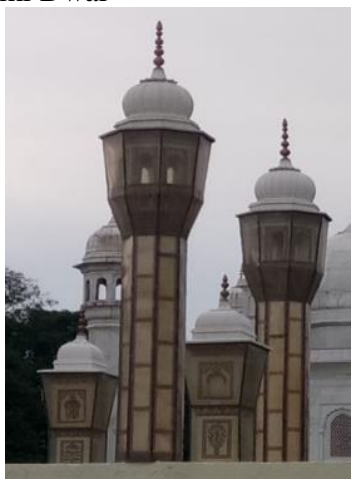

Fig 14(b) Minarets
Darshini Gate comprises of ten minarets, four at corners and others in between (Sketch 10). They are utterly painted with fresco art depicting Mughal, Rajasthani and Kangra Styles. 


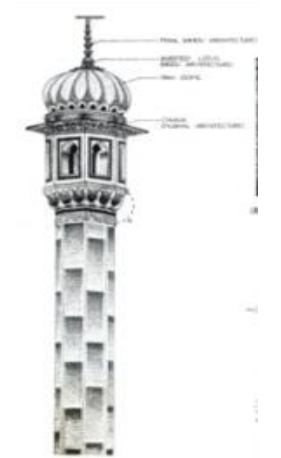

Sketch 11 Minaret 1 (M1)

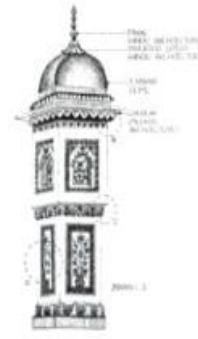

Minaret 2

(M2)

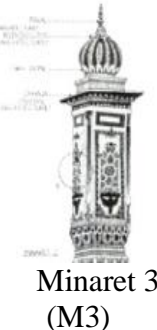

(M3)

Further entering another vestibule, one enters to the main premises. On entering the main Durbar Sahib, (shrine), the beauty of the white marble fascinates the visitors.
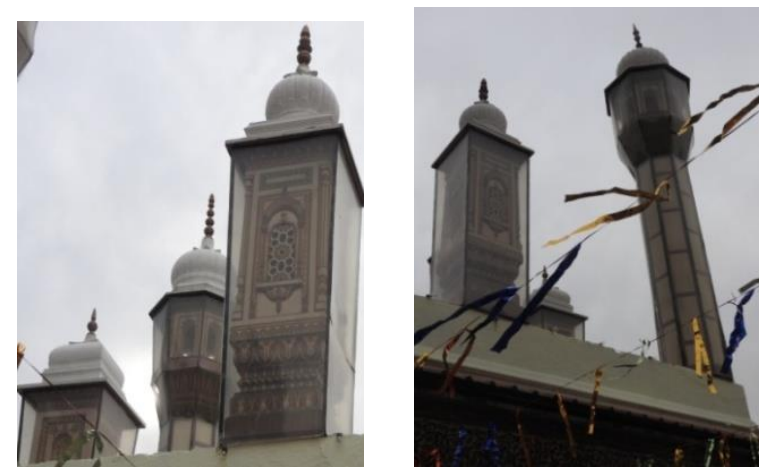

Fig.15 (a), Fig 15 (b). Minarets with floral designs, interlocking patterns and motifs

\section{B. Main Shrine}

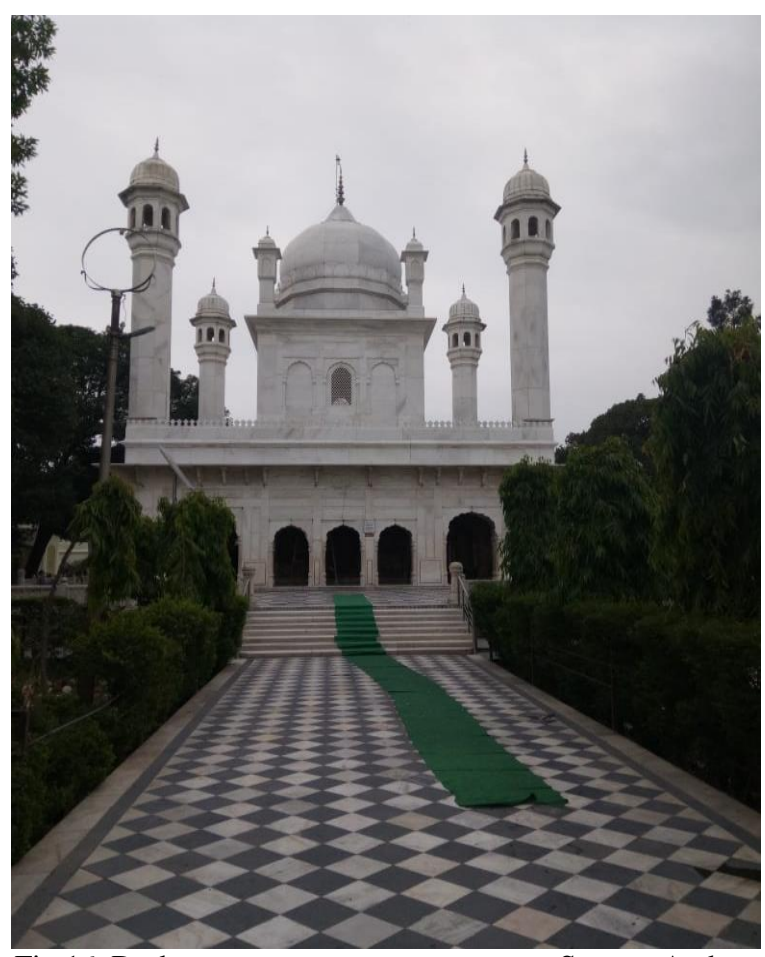

Fig. 16. Durbar

Source: Author

The Shrine stands on the raised platform and there are flower beds and trees surrounding it below on the concept of Char Bagh. Durbar Sahib is symmetric in plan

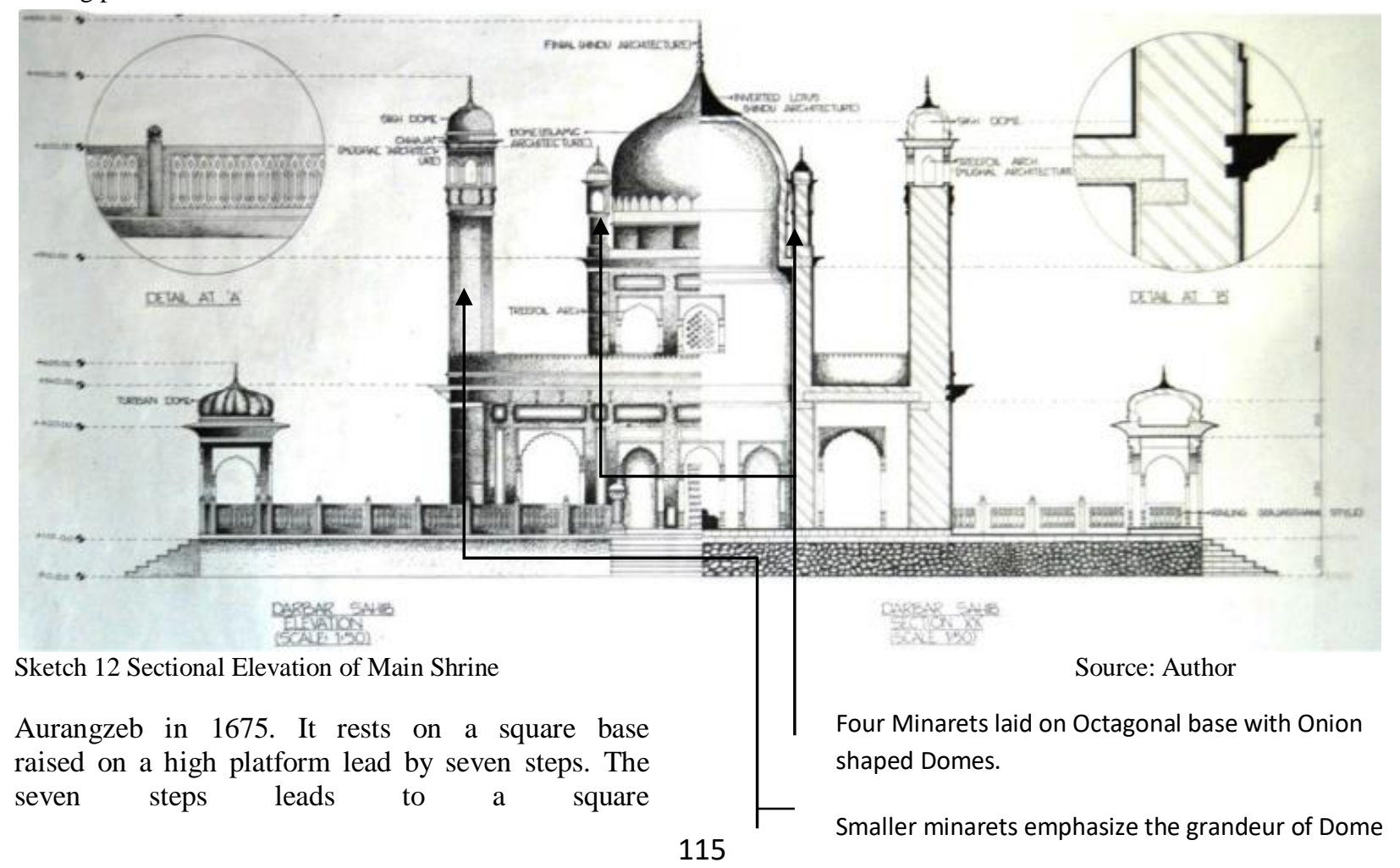


platform $700 \quad \mathrm{~mm}$ high measuring

$2800 \times 2800 \mathrm{~mm}$. The platform comprises of a chatri at each corner for Mata's and an articulate pathway $2500 \mathrm{~mm}$ wide inside which is another chamber where rest the relics of the Guru.

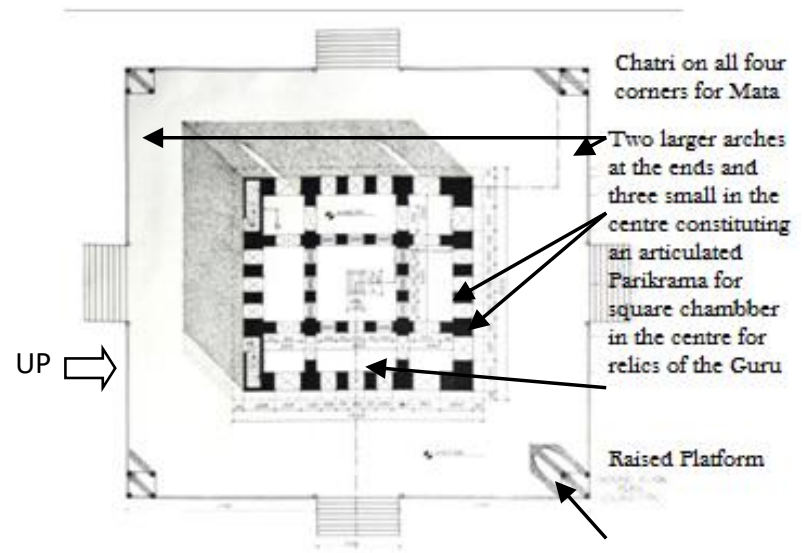

Sketch 13 Plan of Main Shrine Source: Author

minarets are situated, one at each corner of first level and were used to light diyas in ancient times.(Source: Mahant ji) Minarets seem to arise from Ground level and are laid on octagonal base holding onion shaped domes influenced by Sikh Architecture. The minarets of first level are smaller to emphasize the grandeur of Central Dome and minarets. Durbar is a patent conflation of variegated architecture styles which includes Hindu Architecture (The 'Finial' at loftiest and 'Inverted Lotus') Islamic Architecture ('Treefoil' arches and jails), Sikh Architecture ('Dome') and Rajasthani Architecture (Railings). Very similar to The Moti Mosque, in the Red Fort at Shahjahanabad, Delhi built by emperor Aurangzeb (1658-1707) Fig19 which again is an amalgamation of Hindu, Islamic, Sikh architecture.

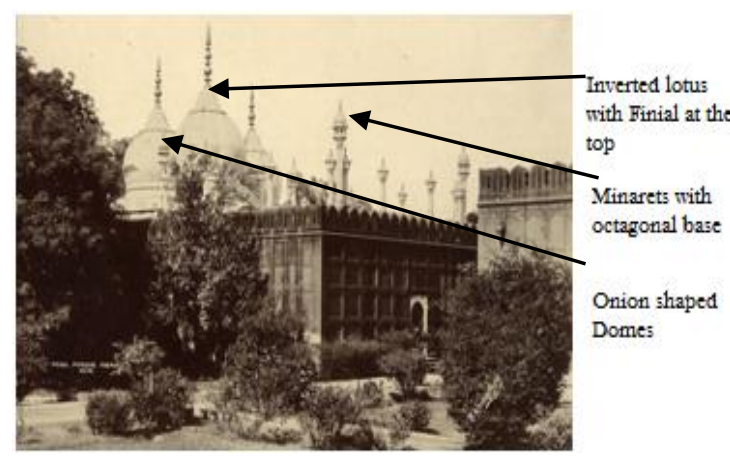

Fig.17. The Moti Mosque, in the Red Fort at Shahjahanabad, Delhi by the sixth Mughal emperor Aurangzeb(16581707).

\section{Mata Chambers/Tombs-}

Samadhi's of all four wives of Guru are co-ordially placed on the four corners.(See Sketch 13).Mata (mother) being the wife of the Guru is treated like a queen. Near the entrance gate, to the left stands the Samadhi (Tomb/ Mata chambers) of Mata Lal Kaur and to the right is the Samadhi of Mata Raj Kaur. On the front courtyard, the Mata Punjab Kaur Samadhi is on the right side and that of Mata Maluki is to the left. There is a pond in between.

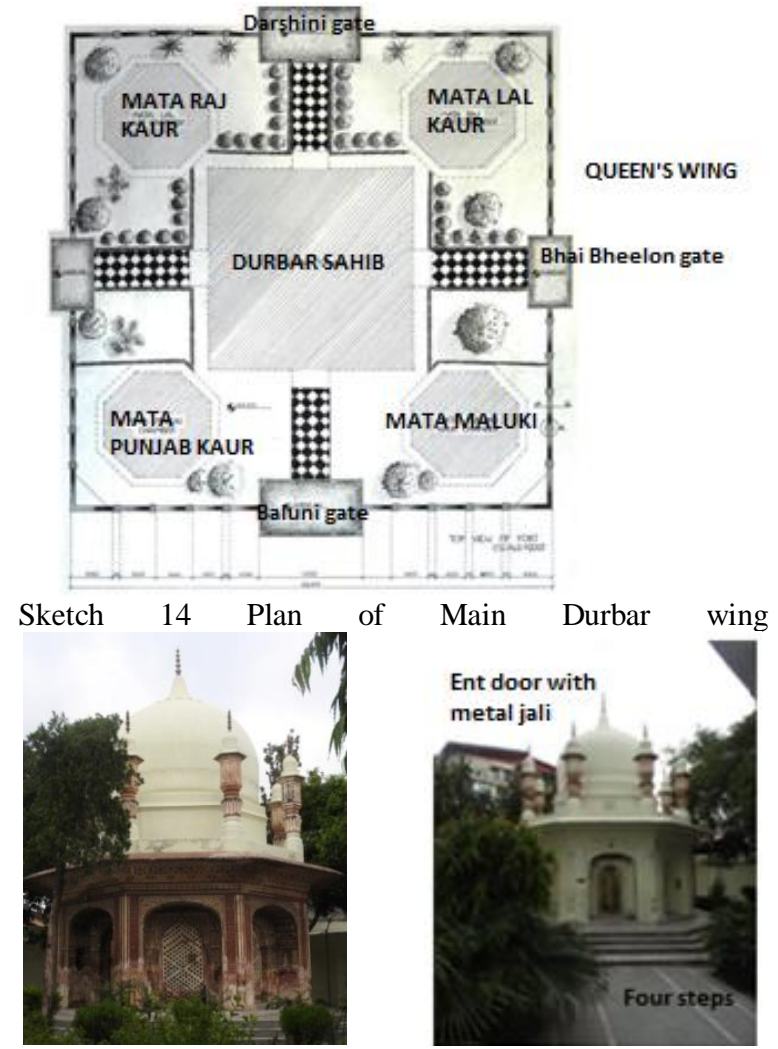

Fig.18 (a). Samadhi of Mata Lal Kaur Fig. 18.(b) Mata Raj Kaur
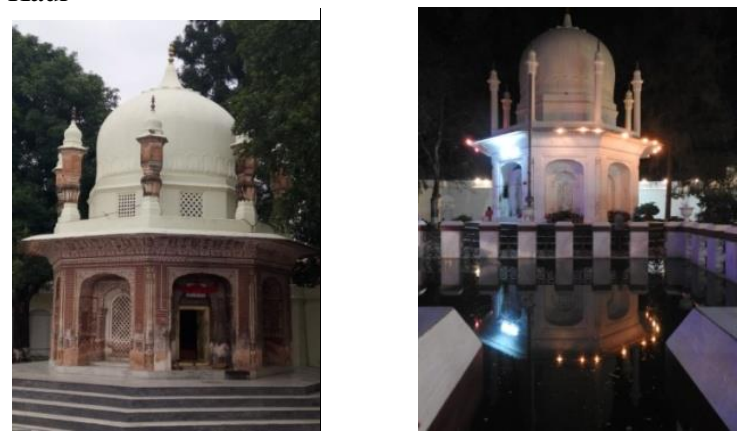

Fig.19 (a)Samadhi of Mata Punjab Kaur Fig.19. (b) Mata Maluki 


\section{International Journal of Engineering Applied Sciences and Technology, 2019 \\ Vol. 4, Issue 8, ISSN No. 2455-2143, Pages 109-118 \\ Published Online December 2019 in IJEAST (http://www.ijeast.com)}

All the four chambers are built on an octagonal platform aided by four steps.

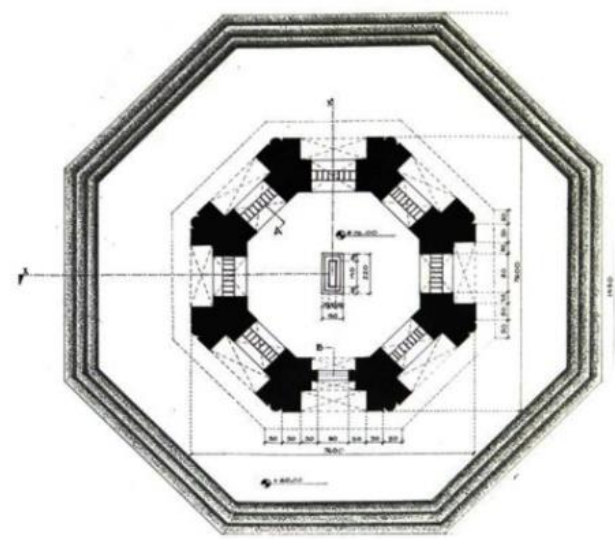

Sketch 15 Typical Plan of Mata Chamber

Each façade of the chamber restrains identical arches that gather details both from Roman and Islamic origin. Seven out of eight faces have mughal jalis and one bears the entrance door that displays metal (cast iron) jali.
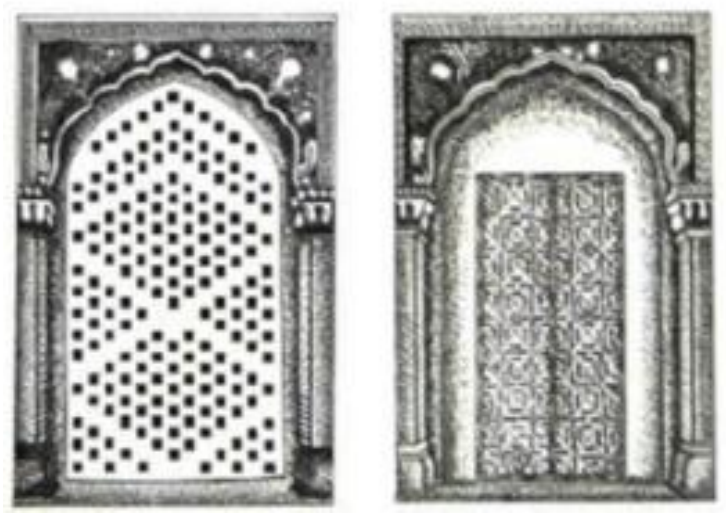

Sketch 16 Mughal jalis 17 Entrance door with metal jali

The door of every chamber faces the main chamber paying devotion to the stature. The dome is in resemblance to that of the main complex has a circular base and rests on an octagonal platform (side $2250 \mathrm{~mm}$ ).Eight minarets are site on the same octagonal platform at each of its corner. The 'Finial' reflects the Hindu Architecture, Dome of Mata's Chambers are purely Islamic with circular base and rests on Octagonal Platform. Floral design at the base of the dome exhibits the Sikh Architecture feature. Eight Minarets look like stalk of flowers, with inlaid decorations and motifs of Hindu Architecture. Frescos are made integral part of the surface of wall, eves and minarets, which throws light on its embellishment.

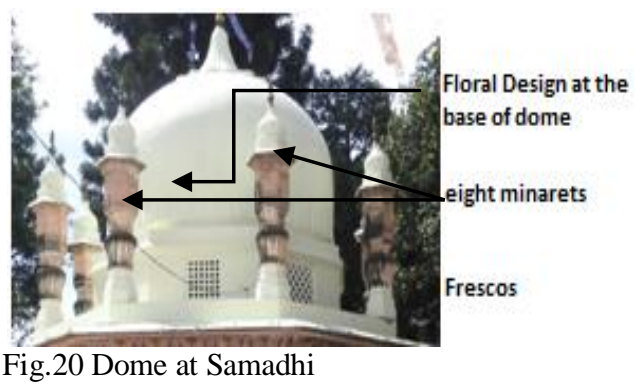

Queen chambers are prominent for frescos depicting images of birds, plants and figurative images, which are inspired by Mughal Architecture. Combination of Trifoil and semi-elliptical arches are deployed on each of the eight faces which is again the amalgamation of Islamic and Hindu Architecture with peculiar Mughal jalis. Pilasters at the end of the arches are influenced by Mughal Period of Shahjahan.

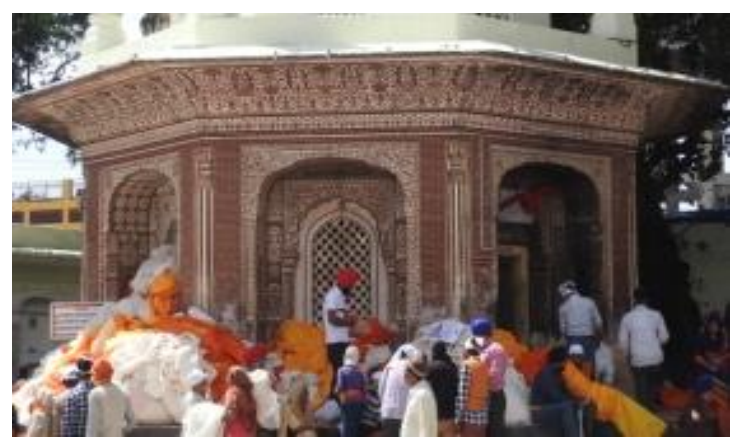

Fig. 21 Arches and frescos at Samadhi Source: Author

\section{MATA'S WING}

\section{A. Bhai Bheelon Gate}

Bhai Baheelon gate is at some distance. Bhai Bheelon used to run the langar and serve food to the hungry.

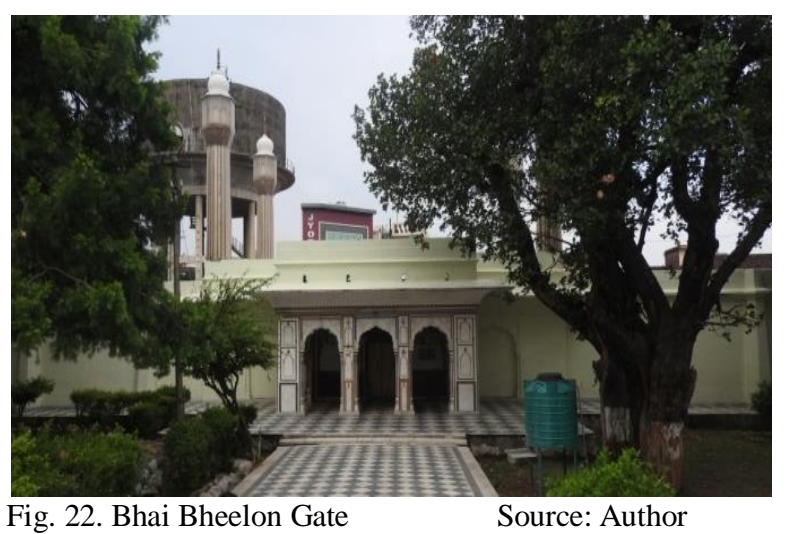




\section{International Journal of Engineering Applied Sciences and Technology, 2019 \\ Vol. 4, Issue 8, ISSN No. 2455-2143, Pages 109-118 \\ Published Online December 2019 in IJEAST (http://www.ijeast.com)}

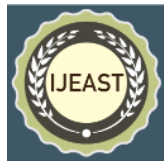

\section{B. Garden}

Inside this gate, is a garden (Mata's wing) with a separate boundary wall towards the North with the step well (now covered with grill) and in the thick of trees in the left stands a pillar which is a symbol of Mata Punjab Kaur's swing.

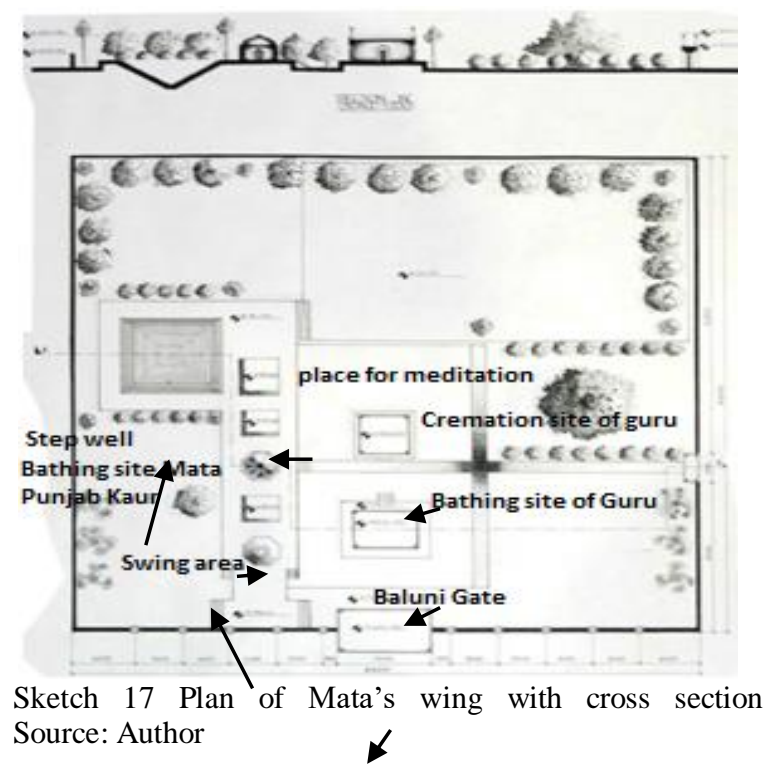

Slightly ahead is the place where she took her last bath. Towards to the right is the place for Guru Maharaj's final bath and little ahead is the place of his cremation.

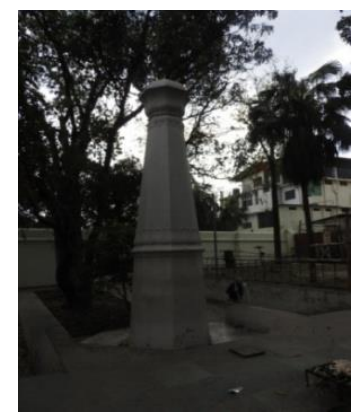

Fig.23. Symbol of Mata Punjab Kaur's swing Ram Rai

\section{CONCLUSION AND ACKNOWLEDGEMENT}

Architecture is not a static phenomenon; it is constantly evolving combination of time and space. Since history Indian architecture has shown resilience to absorb and adopt circumstantial changes and have resolution that it feels integral to Jhanda Sahib. This gurudwara overall signifies the birth of uniting all religion with freedom to person of any religion to adopt it and visit the place. Durbar Sahib is one of the primordial buildings of Dehradun making deep instinct in terms of its being, religion, socio culture and architecture. The complex is a bizarre example of amalgamation of different types of Architecture blended into one. Historic trademark has different influences for architecture in terms of invention of new techniques, historical facts and thus evolution of new architectural culture. Hence, Guru Ram Rai Durbar, is an important component of the living Heritage of the city of Dehradun calls for conservation measures in a scientific and planned manner to ensure the continuity of its high historic and religious significance.

\section{REFERENCES}

[1] Bharati, A. (1963). "Pilgrimage in the Indian tradition. History of Religions, (Pg135-167).

[2] Brooks, G. (2012). Heritage As A Driver For Development Retrieved December 27, 2016, from http://openarchive.icomos.org: http://openarchive.icomos.org/1207/1/III-1Article1_Brooks.pdf

[3] District Census Handbook Dehradun (2011), Uttrakhand Series 06 Part XII-A District Census Handbook Dehradun, village and town directory

[4] Major Leech. R, (1845) Notes on the Religion of the Sikhs and other Sects inhabiting the Punjab: Foreign /Secret Consultation, (Pg144)

[5] Ohri Lokesh, (2019). Been There Doon That? Walking with Laata, Book World Publishers, Dehradun (Pg38-69).

[6] Rein (1858) Udasi Bodh, MS 1858, ff 309 ab: ff 310a, ff 1-320

[7] Singh, R. P. (1995). Towards deeper understanding, Sacredscape and Faithscape: An exploration in pilgrimage studies. National Geographical Journal of India, (Pg89-111).

[8] Singh, Sulakhan(1982). Hetrodoxy in Sikhism: The case of the Udasis: Proceedings of the Indian History Congress ,Vol. 43 (1982), (Pg 383-387)

[9] Williams G. R. C. (1874) Memoir of Dehradun, Publisher Natraj

[10] Wilson H.H. (1958), Civil and Religious institutions of the Sikhs. The Sikh Religion: A Symposium (Pg55)

[11] https://www.euttaranchal.com/tourism/guru-ramrai-gurudwara.php

[12] https://www.sikhiwiki.org/index.php/Baba Ram Rai

[13] https://www.dooncircle.com/guru-ram-raigurudwara-dehradun/ 